\title{
DNA hypomethylation of CD133 promoter is associated with recurrent glioma
}

\author{
BAOLAN SUN ${ }^{1 *}$, ZHENGQIANG WAN $^{4 *}$, JIANHONG SHEN $^{2}$, LANCHUN NI $^{2}$, \\ JIAN CHEN ${ }^{2}, \mathrm{MING} \mathrm{CUI}^{3}, \mathrm{HONGBING} \mathrm{NI}{ }^{3}, \mathrm{WEI} \mathrm{SHI}^{2}$ and JINLONG SHI ${ }^{2}$ \\ ${ }^{1}$ Pediatrics Lab, Research Center of Clinical Medicine, ${ }^{2}$ Department of Neurosurgery, ${ }^{3}$ Laboratory Medicine Center, \\ Affiliated Hospital of Nantong University, Jiangsu 226001; ${ }^{4}$ Department of Neurosurgery, \\ The First People's Hospital of Yancheng, Jiangsu 224001, P.R. China
}

Received February 25, 2016; Accepted June 6, 2016

DOI: $10.3892 / o r .2016 .4880$

\begin{abstract}
Gliomas are the most common type of brain tumor in the central nervous system of adults, and are highly aggressive, resistant to treatment, and prone to recurrence. Brain tumor stem cells (BTSCs) are implicated in tumor initiation and recurrence. Cluster of differentiation (CD)133 is currently the most widely used BTSC marker; however, its role in glioma development and progression is largely unknown. In this study, we evaluated CD133 expression in pairs of primary and recurrent human glioma specimens from 24 patients. We found that recurrent gliomas have aberrantly upregulated CD133 levels. To clarify the mechanism underlying this observation, we assessed CD133 promoter (P)2 methylation status by bisulfite sequencing and found that $\mathrm{P} 2$ hypomethylation was associated with the increase in $C D 133$ expression and glioma recurrence. These results suggest that CD133 overexpression in BTSCs due to $\mathrm{P} 2$ hypomethylation underlies glioma recurrence, which may provide insight into the mechanism of glioma recurrence and provide a basis for novel therapies for glioma treatment.
\end{abstract}

\section{Introduction}

Gliomas are the most common type of intrinsic brain tumor of the central nervous system in adults, and are highly aggressive and insensitive to treatment. Current treatment strategies have not significantly improved long-term survival of patients (1); the median survival is just 12-15 months for patients with glioblastoma (World Health Organization (WHO) IV), 2-5 years for patients with anaplastic glioma (WHO III), and 6-8 years

Correspondence to: Professor Jinlong Shi or Professor Wei Shi, Department of Neurosurgery, Affiliated Hospital of Nantong University, 20 Xisi Road, Nantong, Jiangsu 226001, P.R. China

E-mail:shij@ntu.edu.cn

E-mail: ntshiwei123@163.com

${ }^{*}$ Contributed equally

Key words: glioma, recurrence, CD133, hypomethylation, brain tumor stem cells for patients with low-grade glioma (WHO II) (2). Surgery is the preferred treatment option, which is followed by observation of postoperative remission $(3,4)$. However, even when surgery is combined with chemo- or radiotherapy, relapse is inevitable (5-7).

Human gliomas contain a small population of cells with stem cell-like features known as brain tumor stem cells (BTSCs) (8). These cells are hypothesized to initiate tumor growth and recurrence, since they are resistant to standard anticancer therapies (9). BTSCs may be difficult to remove surgically since they do not form an obvious tumor mass and may not manifest tumor-specific histological features (9).

The stem cell surface antigen cluster of differentiation (CD)133 (also known as AC133 or human prominin-1) is expressed in a subset of neural stem/precursor cells in the adult central nervous system and is a marker used to identify and isolate BTSCs (10). CD133 expression increases with tumor grade and is correlated with glioma patient survival (11); moreover, glioma recurrence can be predicted by an increase in the fraction of CD133-positive cells within the primary tumor (12). However, the regulation of CD133 gene expression in gliomas is not well understood.

Promoter methylation is a mechanism underlying the downregulation of CD133 in colon and ovarian cancers and glioblastoma (13-15). DNA methylation can prevent binding of transcription factors to their target binding sites, thereby repressing transcription. $C D 133$ is transcribed in a tissuespecific manner from five alternative promoters (P1-P5) (16): liver, kidney, pancreas, placenta, lung, spleen, and colon express transcripts containing exons $1 \mathrm{~A}$ and $1 \mathrm{~B}$. On the other hand, exon 1B transcripts are expressed in the brain and ovary, and exon 1A transcripts in the prostate, fetal liver, and small intestine. All CD133 promoters are TATA-less and P1, $\mathrm{P} 2$, and $\mathrm{P} 3$ are located in a $\mathrm{CpG}$ island (16). Recent evidence suggests that DNA methylation of $\mathrm{P} 1$ and $\mathrm{P} 2$ plays a role in the regulation of $C D 133$ expression. $\mathrm{P} 1$ methylation is not tissuespecific, and therefore is not likely to affect transcript levels; in contrast, the tissue-specific methylation of P2 is inversely correlated with CD133 expression (17).

In this study, we analyzed CD133 expression in pairs of primary and recurrent human glioma specimens from 24 patients and found that recurrent gliomas exhibited aberrantly 
upregulated CD133 expression. To clarify the underlying mechanisms, we analyzed $\mathrm{P} 2$ of the $C D 133$ gene by bisulfite sequencing, and found that $C D 133 \mathrm{P} 2$ hypomethylation is associated with increased $C D 133$ gene expression and glioma recurrence.

\section{Materials and methods}

Glioma tissues. Surgical specimens of gliomas were obtained from 24 patients who had undergone tumor resection at Affiliated Hospital of Nantong University from January 2004 to December 2014. The study was approved by the local ethics committee, written informed consent was obtained from all the patients. Recurrence of glioma was defined as the presence of glioma at $>3$ months after surgery for primary glioma. All patients received chemoradiotherapy after the first surgical intervention. Pathological findings were determined by more than 2 pathologists and classified according to the WHO classification standard (Table I). The paired primary and recurrent glioma specimens were from the same patient. For immunohistochemistry, glioma tissue was fixed with $4 \%$ formalin, dehydrated, and then embedded in paraffin. Portions of the tumor tissues were rapidly frozen by liquid nitrogen and stored at $-80^{\circ} \mathrm{C}$ until RNA and DNA extraction for real-time PCR, DNA methylation and western blot analysis.

Cell culture. The U251MG,U87MG, and A172MG glioblastoma cell lines were purchased from the Shanghai Cell Institution of Chinese Academic Sciences, which were cultured as described previously (18). They were maintained in Dulbecco's modified Eagle's medium: nutrient mixture F-12 (MDEM/F12) supplemented with $10 \%$ heat-inactivated fetal bovine serum (FBS), $100 \mathrm{U} / \mathrm{ml}$ penicillin and $100 \mu \mathrm{g} / \mathrm{ml}$ streptomycin (Gibco). Cells were incubated at $37^{\circ} \mathrm{C}$ in a humidified $5 \% \mathrm{CO}_{2}$ air atmosphere. When cell culture reached $50 \%$ confluence, U87MG, U251MG and A172MG cells were treated with 5-Aza-2'-deoxycytidine (5-Aza-dc, A3656; Sigma-Aldrich, St. Louis, MO, USA) at the final concentration of $10 \mathrm{nM}$ for $72 \mathrm{~h}$, respectively.

Western blot analysis. Cells or tissues were washed with cold PBS and lysed in ice-cold RIPA buffer containing protein inhibitors. Cell lysates were incubated on ice for $30 \mathrm{~min}$ and then centrifuged at $4^{\circ} \mathrm{C}$ for $10 \mathrm{~min}$. Supernatants were collected, and protein concentrations were measured. Equivalent amounts of protein in each sample were separated on a $10 \%$ SDS-PAGE gel for separation and then electrotransferred to PVDF membrane. Membranes were blocked and then probed with primary CD133 antibodies ( $2 \mu \mathrm{g} / \mathrm{ml}$, Abcam) followed by the horseradish peroxidase (HRP)-conjugated goat anti-mouse or rabbit $\operatorname{IgG}$ antibodies. Mouse monoclonal anti- $\beta$-actin antibody $(1: 5,000$, Sigma) was used as an internal control. The membranes were developed using an ECL detection system (Pierce, Rockford, IL, USA). The intensity of bands was determined using the Image-Pro Plus 6.0 software. The western blot experiments were repeated at least three times.

RNA extraction and real-time PCR. RNA expression levels of CD133 were determined using quantitative real-time PCR with GAPDH as positive controls. Total mRNA was isolated from glioma specimens and cell lines using mRNA isolation
Table I. WHO grades of glioma patients.

\begin{tabular}{lcc}
\hline & \multicolumn{2}{c}{ WHO grade } \\
\cline { 2 - 3 } Patient & Primary & Recurrent \\
\hline 1 & II & II \\
2 & IV & IV \\
3 & II & IV \\
4 & III & III \\
5 & III & IV \\
6 & II & IV \\
7 & III & IV \\
8 & II & II \\
9 & III & IV \\
10 & IV & IV \\
11 & IV & IV \\
12 & III & III \\
13 & II & II \\
14 & IV & IV \\
15 & IV & IV \\
16 & IV & IV \\
17 & III & III \\
18 & II & IV \\
19 & II & III \\
20 & II & IV \\
21 & IV & IV \\
22 & IV & IV \\
23 & IV & IV \\
24 & IV & IV \\
\hline & &
\end{tabular}

kit (Roche, UK) following the manufacturer's instructions. The concentration and purity of mRNA was determined by ultraviolet spectrophotometry. Isolated mRNA (100 ng) from each sample was transcribed to complementary DNA (cDNA) using a First-Strand cDNA Synthesis kit Roche (Roche), which was then used as a template for quantitative real-time PCR. Primers used for CD133 were 5'-GCACTCTATACCAAAGC GTCAA-3' (sense) and 5'-CTCCCATACTTCTTAGTTTCC TCA-3' (antisense); and for GAPDH primers were 5'-GGAA AGCTGTGGCGTGAT-3' (sense) and 5'-AAGGTGGAAGA ATGGGAGTT-3' (antisense). The primers were designed using Primer 5.0 software and manufactured by TIBmolbiol. After an initial denaturation at $95^{\circ} \mathrm{C}$ for $5 \mathrm{~min}$, the samples were subjected to 40 cycles of RT-PCR $\left(95^{\circ} \mathrm{C}\right.$ for $10 \mathrm{sec}$, annealing temperature $59^{\circ} \mathrm{C}$ for $15 \mathrm{sec}$, and $72^{\circ} \mathrm{C}$ for $20 \mathrm{sec}$ ). At the end of each cycle, the fluorescence emitted was measured in a single step in channel F1 (gain 1). After the 40th cycle, the specimens were heated to $95^{\circ} \mathrm{C}$ and rapidly cooled to $59^{\circ} \mathrm{C}$ for $15 \mathrm{sec}$. All heating and cooling steps were performed with a slope of $20^{\circ} \mathrm{C} / \mathrm{sec}$. The temperature was subsequently raised with a slope of $12^{\circ} \mathrm{C} / \mathrm{sec}$ and fluorescence was measured continuously (channel F1, gain 1) to obtain data for the melting curve analysis. The PCR reaction was subjected to a melting curve analysis to verify the presence of a single amplicon before the PCR products were visualized on agarose 
gels using a gel analyser (SynGene, UK). All PCR reactions were performed in triplicate and a negative control was included that contained primers without DNA.

Immunohistochemical analyses. Serial sections measuring $5 \mu \mathrm{m}$ thick were cut from paraffin blocks and mounted on glass slides coated with $10 \%$ polylysine. Sections were dewaxed in xylene and rehydrated in graded ethanols. Endogenous peroxidase activity was blocked by immersion in $0.3 \%$ methanolic peroxide for $30 \mathrm{~min}$. Immuno-reactivity was enhanced by microwaving and incubating the tissue sections for $10 \mathrm{~min}$ in $0.1 \mathrm{~mol} / 1$ citrate buffer. Tissues were then incubated with an anti-CD133 antibody (1:200, Abcam) overnight at $4^{\circ} \mathrm{C}$. Immuno-staining was performed using the avidin-biotin peroxidase complex method, and antigen-antibody reactions were visualized with chromogen diaminobenzadine. Appropriate positive and negative controls were used. Ten high-power fields were randomly chosen, and $\geq 300$ tumor cells were counted per field. Percentage of cells showing positive staining in cytoplasm/membrane was designated as the CD133 labeling index, as a percentage (\%). The staining procedures were repeated at least three times.

DNA isolation and bisulfite sequencing. With the proteinase $\mathrm{K}$ digestion and phenole-chloroform method, genomic DNA was extracted from frozen tissues (19). Sodium bisulfite treatment of the extracted DNA was performed as previously described (20). In brief, $10 \mu \mathrm{g}$ DNA in $50 \mu 1 \mathrm{TE}$ was incubated with $5.5 \mu 1$ of $0.3 \mathrm{M} \mathrm{NaOH}$ at $37^{\circ} \mathrm{C}$ for $15 \mathrm{~min}$ and $95^{\circ} \mathrm{C}$ for $2 \mathrm{~min}$, and subjected to sodium bisulfite chemical treatment $(2.4 \mathrm{M}$ sodium metabisulfite; $0.5 \mathrm{mM}$ hydroquinone, $\mathrm{pH}$ 5.0, both from Sigma). Following incubation at $55^{\circ} \mathrm{C}$ for $4 \mathrm{~h}$, the treated DNA was purified using the SK1261 kit (Shenggong, China), desulfonated in $0.3 \mathrm{M} \mathrm{NaOH}$, neutralized to $\mathrm{pH} 7.0$ using $3 \mathrm{M}$ sodium acetate ( $\mathrm{pH}$ 5.2). The neutralized DNA was purified using SK1261 purification kit again, dissolved in TE buffer ( $\mathrm{pH}$ 8.0).

The primers (fwd: 5'-TYGYGGTGAGTATGTTTAAGG-3', rev: 5'-ACCCAACTACTCACCRTACACC-3') were designed to amplify the promoter 2 from -237 to +52 for bisulfite genomic sequencing. An initial denaturation at $98^{\circ} \mathrm{C}$ for 4 min was followed by five PCR cycles of $94^{\circ} \mathrm{C}$ for $45 \mathrm{sec}, 68^{\circ} \mathrm{C}$ for $45 \mathrm{sec}$ and $72^{\circ} \mathrm{C}$ for $1 \mathrm{~min}$. The PCR was then completed with 35 cycles of $45 \mathrm{sec}$ at $95^{\circ} \mathrm{C}, 45 \mathrm{sec}$ at $58^{\circ} \mathrm{C}$. The amplified products were gel-purified using the SK1261 kit and subjected to TA-cloning using pUC18-T vector (Shenggong, Biotechnology Co.). Ten clones for each case were selected for sequencing using BigDye version 3.1, and analyzed on automated DNA sequence analyzer (ABI PRISM 3730; Applied Biosystems, Inc., Foster City, CA, USA). The cytosine or thymine residues at the $\mathrm{CpG}$ sites represented methylated or unmethylated status, respectively.

Statistical analyses. Statistical analysis was performed using SPSS 13.0 for Windows. Data are expressed as median and 25-75 percentiles [median (25th percentile, 75th percentile)]. Mann-Whitney U test was used to determine the differences of CD133 expression between primary and recurrent tumor. Paired t-test was used to analyze the differences of CD133 expression between the treated glioma cell lines. The correlation between CD133 DNA methylation and mRNA expression was analyzed by Pearson's correlation test. All statistical tests

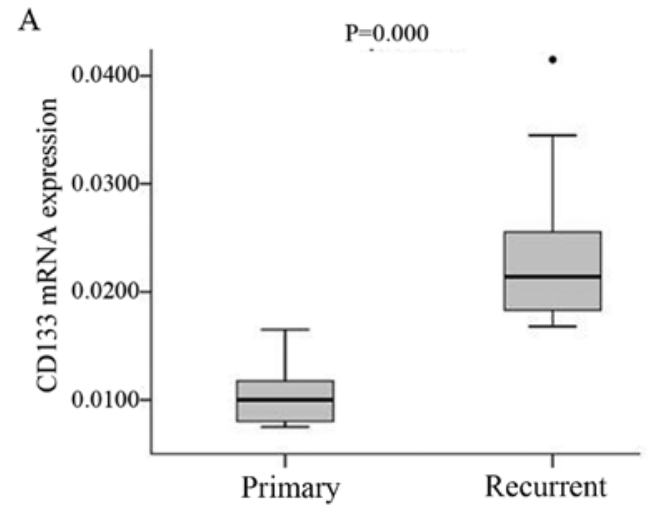

B

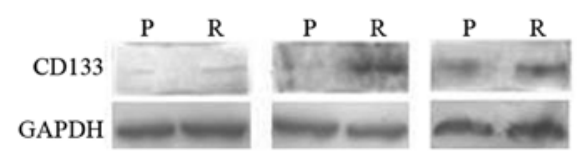

C

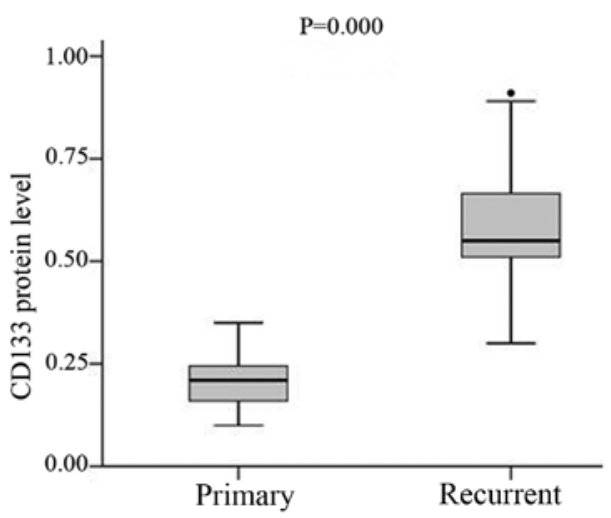

Figure 1. CD133 expression in pairs of primary and recurrent glioma. (A) CD133 mRNA relative levels by real-time PCR. The value was quantified compared with GAPDH. (B) CD133 protein levels by western blotting. The blot shows representative results from the pairs of primary and recurrent gliomas. GAPDH was used as a loading control. P, primary gliomas; $\mathrm{R}$, recurrent gliomas. (C) Statistical analysis of CD133 protein in primary and recurrent gliomas. Data are presented as box plots, where the lines inside the boxes represent the medians, the boxes represent the 25 th and 75 th percentiles, and the lines outside the boxes represent the 10th and 90th percentiles.

were calculated two-sided and values of $\mathrm{P}<0.05$ was considered to be statistically significant.

\section{Results}

CD133 expression is upregulated in recurrent glioma. CD133 mRNA and protein expression in primary and recurrent glioma specimens was assessed by real-time PCR and western blotting, respectively. While CD133 transcript was detected in all specimens, the levels were higher in recurrent (median 0.0214 ; range, $0.0182-0.0249$ ) than in primary glioma (median 0.1,000; range, 0.0080-0.0119, $\mathrm{P}<0.001$ ) (Fig. 1A). A similar trend was observed for CD133 protein level (Fig. 1B and C).

CD133-positive cell number is increased in recurrent as compared to primary glioma. CD133 protein expression and localization in glioma specimens were evaluated by immunohistochemistry. CD133-positive cells were detected in all specimens, and expression was mainly observed in the cytoplasm and plasma membrane (Fig. 2A). The percentage 

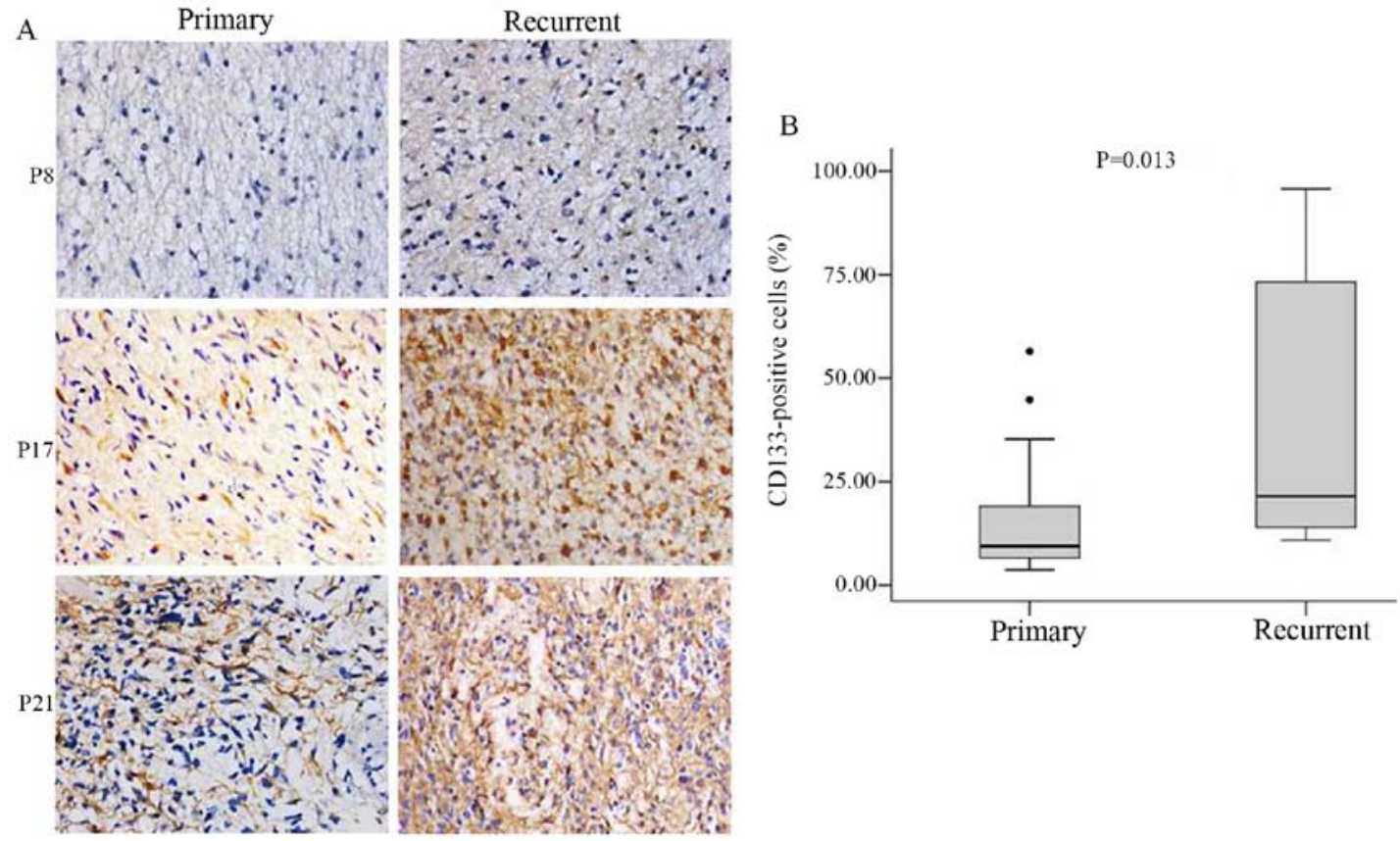

Figure 2. CD133-positive cell number is increased in recurrent glioma by IHC. (A) CD133 expression in paraffin-embedded sections from representative 3 pairs of primary and recurrent gliomas. CD133 expression was primarily localized in the cytoplasma and the membrane of tumor cells (brown). (B) Statistical analysis of the percentage of CD133-positive cell number in primary and recurrent gliomas. Data are presented as box plots, where the lines inside the boxes represent the medians, the boxes represent the 25th and 75th percentiles, and the lines outside the boxes represent the 10th and 90th percentiles.

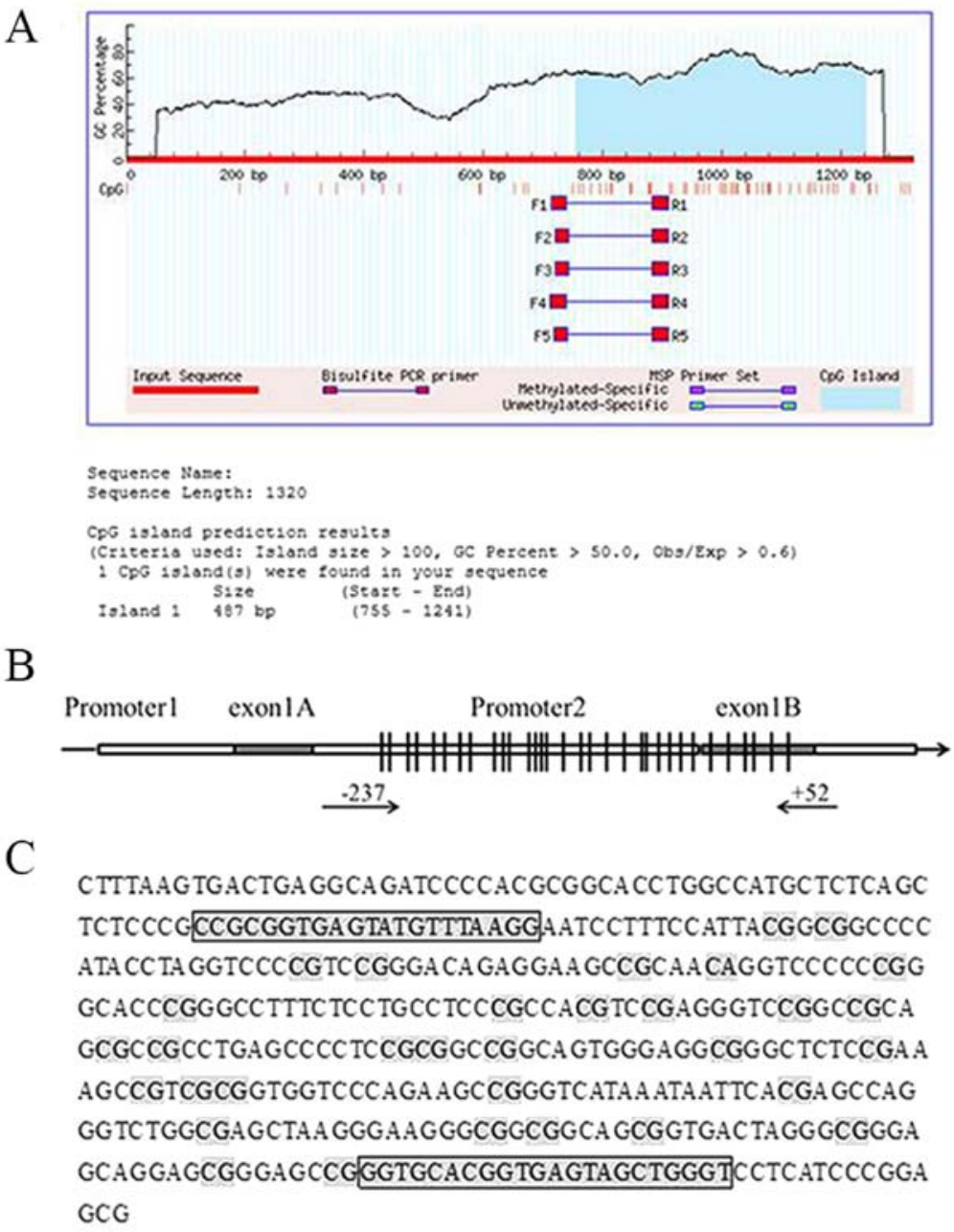

Figure 3. The diagram of $\mathrm{CpG}$ islands in CD133. (A) Structure of CD133 promoter, showing one $\mathrm{CpG}$ island (blue-shaded region). (B) The sketch of detection region. (C) Sequence of $\mathrm{CpG}$ island. The bisulfite sequencing PCR primers are boxed. Thirty-two CpG sites are labeled with gray background. 
A
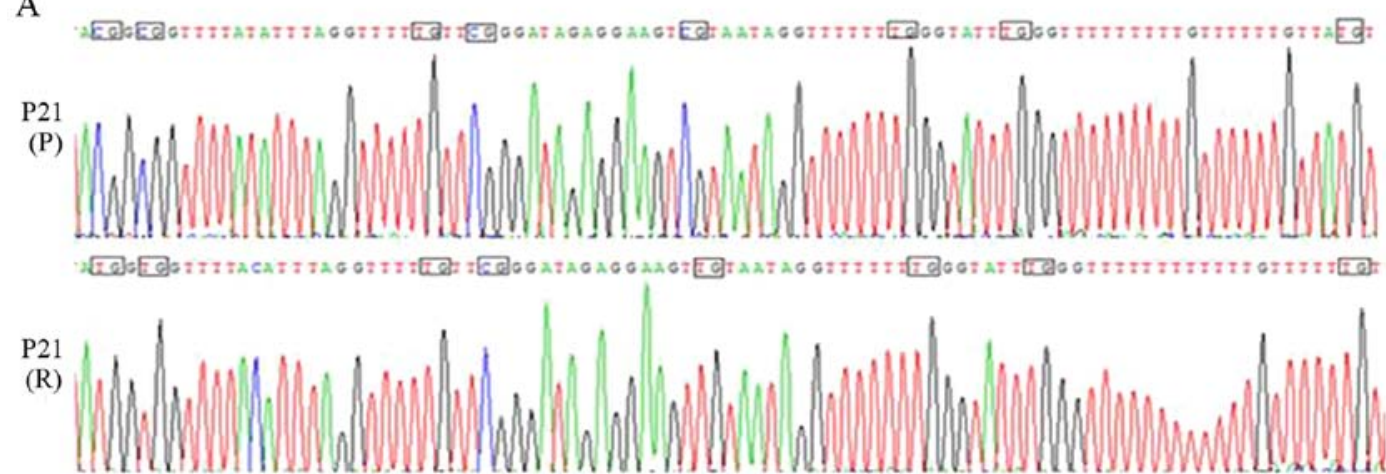

B

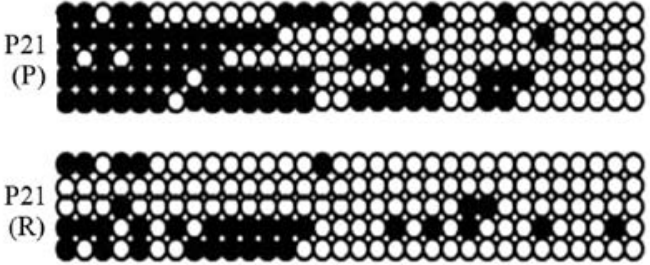

$\mathrm{C}$

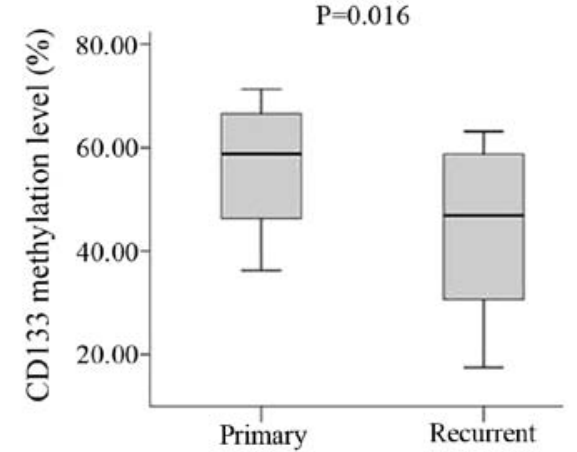

Figure 4. Hypomethylation of the CD133 promoter in recurrent glioma. (A) Sequencing of CpG island. CG represents methylated, TG represents unmethylated. (B) Methylation patterns of $\mathrm{CpG}$ island. Black and white circles represent methylated and unmethylated sites, respectively. (C) Statistical analysis of CD133 promoter methylation in primary and recurrent gliomas. Data are presented as box plots, where the lines inside the boxes represent the medians, the boxes represent the 25 th and 75 th percentiles, and the lines outside the boxes represent the 10th and 90th percentiles.

of CD133-positive cells was significantly higher in recurrent (median $12.99 \%$; range, 3.94-58.23\%) as compared to primary glioma (median 4.35\%; range, 2.43-14.35\%, $\mathrm{P}<0.05$ ) (Fig. 2B).

Hypomethylation of the CD133 promoter increases CD133 expression in recurrent glioma. To clarify the mechanism underlying the upregulation of CD133 level in recurrent glioma, we analyzed the methylation status of $\mathrm{CpG}$ islands in the $C D 133$ promoter. A sequence analysis revealed that the CD133 P2 promoter contains a 487-bp CpG island, with a GC content $>50 \%$ and a $\mathrm{CpG}$ ratio (Obs/Exp) $>0.6$ (Fig. 3A). The $\mathrm{P} 2$ promoter region $(-237$ to +52$)$ contained $32 \mathrm{CpG}$ sites, as determined by bisulfite genomic sequencing (Fig. 3B and C). The 332-bp CD133 target fragment was cloned and sequenced, revealing unmethylated $\mathrm{C}$ residues that were completely converted to $\mathrm{U}$ by bisulfite treatment; these were replaced by $\mathrm{T}$ following PCR amplification. In contrast, methylated $\mathrm{C}$ residues persisted after bisulfite treatment, indicating that $\mathrm{CpG}$ islands of the $\mathrm{CD} 133$ promoter were methylated (Fig. 4A and B). However, DNA methylation levels were lower in recurrent (median, 46.88\%; range, 26.56-59.69\%) as compared to primary glioma (median, 58.76\%; range, 42.19-67.35\%, $\mathrm{P}<0.05$ ) (Fig. 4C). Correlation analysis showed a negative relationship between DNA methylation and $\mathrm{CD} 133$ expression levels $(\mathrm{r}=-0.715, \mathrm{P}<0.05)$.

Promoter demethylation leads to upregulation of CD133 expression. To assess the effects of demethylation in vitro, we treated U87, U251, and A172 glioma cells with the demethylating agent 5 -aza-2'-deoxycytidine (10 $\mu \mathrm{M}$ for $72 \mathrm{~h})$. CD133 mRNA expression was upregulated in these cells by 2.15 ,

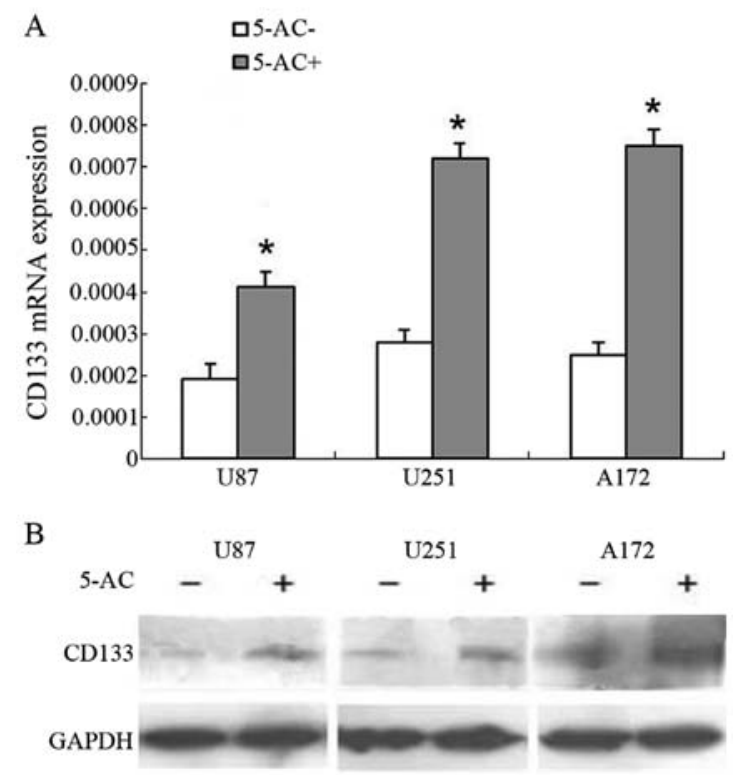

Figure 5. CD133 expression in glioma cell lines after treatmeat with 5-AC. (A) Real-time PCR analysis of CD133 mRNA expression. Error bars represent the standard deviation. Compared with untreated group ${ }^{*} \mathrm{P}<0.05$. (B) Western blot analysis of CD133 protein levels. GAPDH was used as a loading control.

2.56, and 3.03-fold, respectively (Fig. 5A). A similar trend was observed for $\mathrm{CD} 133$ protein expression (Fig. 5B). These results indicate that CD133 demethylation increases CD133 level in glioma. 


\section{Discussion}

BTSCs are thought to be the main determinants of the occurrence, development, metastasis, recurrence, and treatment sensitivity of malignant glioma (21). BTSCs can form the same pathological type of tumor as the parent tumor both in vitro and in vivo $(22,23)$. However, the direct study of BTSCs is challenging due to the lack of specific markers. In theory, expression levels of stem cell-related genes represent changes in the BTSC population of gliomas. The most common stem cell-related genes are nestin, CD133, ATP-binding cassette superfamily $G$ member 2, SRY box-containing gene 2, POU class 5 homeobox 1/OCT4, and musashi-1. In our previous study we reported the expression and methylation status of OCT4 in glioma (18). Based on these findings and other previous reports, we hypothesized that BTSCs initiate gliomas and are responsible for their recurrence.

CD133 is a cell membrane glycoprotein that has been identified as a marker of a subset of BTSCs in the adult central nervous system and in glioblastoma stem-like cells $(10,11)$. CD133-positive cells exhibit stem cell-like qualities in vitro and are capable of tumor formation in vivo (24). CD133-positive BTSCs in an animal model showed an unlimited capacity for self-renewal and for inducing tumor initiation and progression (25). CD133 has been isolated from hematopoietic stem cells using an antibody that recognizes the AC133 epitope, and is used as a marker for the isolation of brain cancer stem cells (26).

In this study, we determined that CD133 expression was upregulated in recurrent as compared to newly diagnosed glioma specimens. This suggests that there were more residual BTSCs in recurrent than in primary glioma. Surgery is an invasive procedure that is accompanied by tissue injury, the production of inflammatory cytokines, angiogenesis, and glioma cell proliferation, which can lead to changes in the local microenvironment and the recruitment of residual BTSCs to the surgery site. The proliferation of BTSCs and their differentiation into glioma cells $(27,28)$ result in the upregulation of CD133 expression and glioma recurrence.

Changes in DNA methylation patterns are an important hallmark of tumor development and progression (29). CD133 contains five alternative promoters, three of which are partly regulated by methylation (16). AC133 promoters are TATAless and three (P1-P3) are located within a $\mathrm{CpG}$ island. In vitro methylation suppressed the activity of $\mathrm{P} 1$ and $\mathrm{P} 2$, and recent studies have shown that DNA methylation is inversely correlated with $C D 133$ transcription $(13,30,31)$. Here, we found that CD133 transcription in glioblastoma is dependent on DNA hypomethylation, which has been shown to promote tumorigenesis by inducing the activation of oncogenes and/or causing genomic instability (32). Thus, $C D 133$ promoter hypomethylation may be associated with the maintenance of BTSCs in brain tumors. It has been proposed that a reduction in overall genomic methylation, an important feature of tumor cells, is responsible for decreased methylation of specific genes (33).

Treatment of glioma cell lines with a demethylating agent increased CD133 mRNA and protein expression, which was consistent with changes reported for some oncogenes (34). DNA methylation status regulates the transition from CD133 transcriptional activation to repression in glioma. DNA meth- ylation is reversible; as such, methylation status and consequent dysregulation of target gene expression can be altered by drug treatment (35). In conclusion, the results of this study provide insight into the mechanism of glioma recurrence and provide a basis for novel therapies for glioma treatment.

\section{Acknowledgements}

This study was supported by the Youth Fund of the National Natural Science Foundation of China (81201975, 81201349), China Postdoctoral Science Foundation (2015M581845), the Six Major Human Resources Project of Jiangsu Province (2013-WSN-077, 2014-WSW-031), the Health Department Project of Jiangsu Province (H201422) and the Translational Medicine Foundation of Affiliated Hospital of Nantong University (TDFzh2014015).

\section{References}

1. Braganza MZ, Kitahara CM, Berrington de González A, Inskip PD, Johnson KJ and Rajaraman P: Ionizing radiation and the risk of brain and central nervous system tumors: A systematic review. Neuro-oncol 14: 1316-1324, 2012.

2. Wen PY and Kesari S: Malignant gliomas in adults. N Engl J Med 359: 492-507, 2008.

3. Gonzalez J and Gilbert MR: Treatment of astrocytomas. Curr Opin Neurol 18: 632-638, 2005.

4. Hentschel SJ and Lang FF: Current surgical management of glioblastoma. Cancer J 9: 113-125, 2003.

5. Wallner KE, Galicich JH, Krol G, Arbit E and Malkin MG: Patterns of failure following treatment for glioblastoma multiforme and anaplastic astrocytoma. Int J Radiat Oncol Biol Phys 16: 1405-1409, 1989

6. Sneed PK, Gutin PH, Larson DA, Malec MK, Phillips TL, Prados MD, Scharfen CO, Weaver KA and Wara WM: Patterns of recurrence of glioblastoma multiforme after external irradiation followed by implant boost. Int J Radiat Oncol Biol Phys 29: 719-727, 1994.

7. Aydin H, Sillenberg I and von Lieven H: Patterns of failure following CT-based 3-D irradiation for malignant glioma. Strahlenther Onkol 177: 424-431, 2001.

8. Kim SS, Pirollo KF and Chang EH: Isolation and culturing of glioma cancer stem cells. Curr Protoc Cell Biol: 23.10.1-23.10.10, 2015.

9. Lathia JD, Mack SC, Mulkearns-Hubert EE, Valentim CL and Rich JN: Cancer stem cells in glioblastoma. Genes Dev 29: 1203-1217, 2015.

10. Zhang H and Li SY: Research progression of CD133 as a marker of cancer stem cells. Clin J Cancer 29: 243-247, 2010.

11. Zeppernick F, Ahmadi R, Campos B, Dictus C, Helmke BM, Becker N, Lichter P, Unterberg A, Radlwimmer B and HeroldMende CC: Stem cell marker CD133 affects clinical outcome in glioma patients. Clin Cancer Res 14: 123-129, 2008.

12. Auffinger B, Tobias AL, Han Y, Lee G, Guo D, Dey M, Lesniak MS and Ahmed AU: Conversion of differentiated cancer cells into cancer stem-like cells in a glioblastoma model after primary chemotherapy. Cell Death Differ 21: 1119-1131, 2014.

13. Jeon YK, Kim SH, Choi SH, Kim KH, Yoo BC, Ku JL and Park JG: Promoter hypermethylation and loss of CD133 gene expression in colorectal cancers. World J Gastroenterol 16: 3153-3160, 2010.

14. Min KJ, So KA, Ouh YT, Hong JH and Lee JK: The effects of DNA methylation and epigenetic factors on the expression of CD133 in ovarian cancers. J Ovarian Res 5: 28, 2012.

15. Gopisetty G, Xu J, Sampath D, Colman H and Puduvalli VK: Epigenetic regulation of CD133/PROM1 expression in glioma stem cells by Spl/myc and promoter methylation. Oncogene 32: 3119-3129, 2013.

16. Shmelkov SV, Jun L, St Clair R, McGarrigle D, Derderian CA, Usenko JK, Costa C, Zhang F, Guo X and Rafii S: Alternative promoters regulate transcription of the gene that encodes stem cell surface protein AC133. Blood 103: 2055-2061, 2004. 
17. Tabu K, Sasai K, Kimura T, Wang L, Aoyanagi E, Kohsaka S, Tanino M, Nishihara H and Tanaka S: Promoter hypomethylation regulates CD133 expression in human gliomas. Cell Res 18 1037-1046, 2008.

18. Shi J, Shi W, Ni L, Xu X, Su X, Xia L, Xu F, Chen J and Zhu J: OCT4 is epigenetically regulated by DNA hypomethylation of promoter and exon in primary gliomas. Oncol Rep 30: 201-206, 2013.

19. Bigner SH, Matthews MR, Rasheed BK, Wiltshire RN, Friedman HS, Friedman AH, Stenzel TT, Dawes DM, McLendon RE and Bigner DD: Molecular genetic aspects of oligodendrogliomas including analysis by comparative genomic hybridization. Am J Pathol 155: 375-386, 1999.

20. Jansen GA, Mihalik SJ, Watkins PA, Moser HW, Jakobs C, Denis $\mathrm{S}$ and Wanders RJ: Phytanoyl-CoA hydroxylase is present in human liver, located in peroxisomes, and deficient in Zellweger syndrome: Direct, unequivocal evidence for the new, revised pathway of phytanic acid alpha-oxidation in humans. Biochem Biophys Res Commun 229: 205-210, 1996.

21. Germano I, Swiss V and Casaccia P: Primary brain tumors, neural stem cell, and brain tumor cancer cells: Where is the link? Neuropharmacology 58: 903-910, 2010.

22. He H, Li MW and Niu CS: The pathological characteristics of glioma stem cell niches. J Clin Neurosci 19: 121-127, 2012.

23. Achanta P, Sedora Roman NI and Quiñones-Hinojosa A: Gliomagenesis and the use of neural stem cells in brain tumor treatment. Anticancer Agents Med Chem 10: 121-130, 2010.

24. Schwab LP, Peacock DL, Majumdar D, Ingels JF, Jensen LC, Smith KD, Cushing RC and Seagroves TN: Hypoxia-inducible factor $1 \alpha$ promotes primary tumor growth and tumor-initiating cell activity in breast cancer. Breast Cancer Res 14: R6, 2012.

25. Chakraborty S, Kanakasabai S and Bright JJ: Constitutive androstane receptor agonist CITCO inhibits growth and expansion of brain tumour stem cells. Br J Cancer 104: 448-459, 2011.

26. Kahlert UD, Maciaczyk D, Dai F, Claus R, Firat E, Doostkam S, Bogiel T, Carro MS,Döbrössy M,Herold-Mende C, et al: Resistance to hypoxia-induced, BNIP3-mediated cell death contributes to an increase in a CD133-positive cell population in human glioblastomas in vitro. J Neuropathol Exp Neurol 71: 1086-1099, 2012.
27. Liu G, Yuan X, Zeng Z, Tunici P, Ng H, Abdulkadir IR, Lu L, Irvin D, Black KL and Yu JS: Analysis of gene expression and chemoresistance of $\mathrm{CD} 133^{+}$cancer stem cells in glioblastoma. Mol Cancer 5: 67, 2006.

28. Liu JM, Mao BY, Hong S, Liu YH and Wang XJ: The postoperative brain tumour stem cell (BTSC) niche and cancer recurrence. Adv Ther 25: 389-398, 2008.

29. Gómez-Díaz E, Jordà M, Peinado MA and Rivero A: Epigenetics of host-pathogen interactions: The road ahead and the road behind. PLoS Pathog 8: e1003007, 2012.

30. Baba T, Convery PA, Matsumura N, Whitaker RS, Kondoh E, Perry T, Huang Z, Bentley RC, Mori S, Fujii S, et al: Epigenetic regulation of $\mathrm{CD} 133$ and tumorigenicity of $\mathrm{CD} 133^{+}$ovarian cancer cells. Oncogene 28: 209-218, 2009.

31. He J, Shan Z, Li L, Liu F, Liu Z, Song M and Zhu H: Expression of glioma stem cell marker CD133 and O6-methylguanine-DNA methyltransferase is associated with resistance to radiotherapy in gliomas. Oncol Rep 26: 1305-1313, 2011.

32. Mudbhary R, Hoshida Y, Chernyavskaya Y, Jacob V, Villanueva A, Fiel MI, Chen X, Kojima K, Thung S, Bronson RT, et al: UHRF1 overexpression drives DNA hypomethylation and hepatocellular carcinoma. Cancer Cell 25: 196-209, 2014.

33. Hackett JA and Surani MA: DNA methylation dynamics during the mammalian life cycle. Philos Trans R Soc Lond B Biol Sci 368: 20110328, 2013.

34. Krutovskikh V and Partensky C: New insights in oncology: Epigenetics and cancer stem cells. Cancer Radiother 15: 716-722, 2011 (In French).

35. Radpour R, Barekati Z, Kohler C, Schumacher MM, Grussenmeyer T, Jenoe P, Hartmann N, Moes S, Letzkus M, Bitzer J, et al: Integrated epigenetics of human breast cancer: Synoptic investigation of targeted genes, microRNAs and proteins upon demethylation treatment. PLoS One 6: e27355, 2011. 